Research Article

\title{
New Framework of Digital Entrepreneurship Model Based on Artificial Intelligence and Cloud Computing
}

\author{
Jiahui Li (iD) and Meifang Yao \\ School of Management, Jilin University, Changchun 130012, Jilin, China \\ Correspondence should be addressed to Jiahui Li; jiahuil18@mails.jlu.edu.cn
}

Received 16 June 2021; Revised 9 July 2021; Accepted 1 September 2021; Published 28 September 2021

Academic Editor: Sang-Bing Tsai

Copyright (C) 2021 Jiahui Li and Meifang Yao. This is an open access article distributed under the Creative Commons Attribution License, which permits unrestricted use, distribution, and reproduction in any medium, provided the original work is properly cited.

\begin{abstract}
With the rapid development of entrepreneurial enterprises and the widespread application of emerging technologies, the commercialization of new technologies for entrepreneurial enterprises is particularly important. This research mainly discusses the new framework of digital entrepreneurship model based on artificial intelligence and cloud computing. Through artificial intelligence technology, the products provided by existing competitors only have the characteristics of one-way value; that is, data is only collected and displayed, and the application of artificial intelligence technology in products makes the value of products develop in two directions; that is, the machine can self-identify faults and errors are resolved and reported. Let customers experience the convenience, accuracy, and safety brought by technology through intelligent acquisition equipment hardware with artificial intelligence algorithm analysis and camera hardware with artificial intelligence image analysis. Customers can pay flexibly according to their needs. This model greatly enhances the high possibility of artificial intelligence companies landing. Use big data analysis and cloud computing technology to provide customers with a series of solutions such as warehouse management, sales forecasting, big data analysis, and financial management. In the SaaS market, in terms of market segmentation, there are no domestic enterprises with scale and brand effect; the incentive and welfare module will focus on the outsourcing and outsourcing of employee benefits. Relevant value-added services and derivative services are the core business, which can give play to the competitive advantages of specialization, scale, and platform. From 2018 to 2020, the cash paid to employees shows a gradual increase, and the taxes and fees paid are also increasing year by year. The cash paid for other operating activities reached a maximum of 12303 million yuan in 2018. This research will promote the innovation of new types of enterprises.
\end{abstract}

\section{Introduction}

In recent years, entrepreneurship has increasingly become a hot spot in society. Startup companies have opened up new market spaces and have greatly promoted the rapid growth of the Chinese economy and the ability to resist risks. The development of regional economy by innovative enterprises is mainly reflected in three aspects. One is that it can increase employment opportunities, the second is that it can promote the development of regional high-tech industries, and the third is that it can promote and shape regional innovation clusters and promote the formation of regional magnetic field effects.

How to use the social talents, science and technology, and resource advantages to effectively promote the prosperity of the regional economy, realize the transformation of production, education, and research, and play the role of university spin-offs is of great significance. Therefore, based on the perspective of entrepreneurial environment, this article discusses the entrepreneurial model of new-born enterprises, hoping to provide some theoretical and mental references for entrepreneurial practice, thereby increasing the success rate of regional enterprises and promoting regional development and prosperity.

With the rapid development of cloud computing technology, its security issues have become more and more obvious and have received extensive attention from the industry and academia. Srinivasamurthy believes that high security risks are very common in traditional cloud architectures. Invading virtual machines destroys the availability of cloud 
services or resources. From the perspective of security and privacy protection technology in cloud computing, he first introduced the related research progress of cloud virtualization security, cloud data security, and cloud application security. In addition, he also analyzed the characteristics and application scope of typical solutions and compared their different effectiveness in security defense and privacy protection. Although he discussed the current limitations and possible future research directions, the research innovation is not good [1]. Chen formulates the decision-making problem of distributed computing offloading among mobile device users. He analyzed the structural nature of the game and proved that the game has limited improvements. Although he designed a distributed computing shunt algorithm, the game theory method he adopted is unreasonable [2]. Cloud computing allows users to consume various IT resources on demand and has low management overhead. Han believes that customers may face new security risks when using cloud computing platforms. He chose to solve the problem from different angles, by studying how to improve the virtual machine allocation strategy, so that it is difficult for the attacker to colocate with the target. He defined security indicators used to assess attacks, modeled these indicators, and compared the difficulty of achieving coexistence under three common policies and designed a new strategy that not only mitigates the threat of attacks, but also meets the balance of workload and low power requirements. Although he improved the virtual machine allocation strategy, his research scheme is not novel enough [3]. Xu believes that, in the cloud computing paradigm, due to the existence of heterogeneous applications (for example, content delivery networks, MapReduce, and web applications), workloads have controversial allocation requirements in terms of ICT resource capacity. Therefore, his main purpose is to identify open challenges related to energy-saving resource allocation. Although he outlined the problem and the existing hardware- and software-based technologies available for this purpose, the study lacked experimental data [4].

Through artificial intelligence technology, the products provided by existing competitors only have the characteristics of one-way value; that is, data is only collected and displayed, and the application of artificial intelligence technology in products makes the value of products develop in two directions; that is, the machine can self-identify faults and errors are resolved and reported. Let customers experience the convenience, accuracy, and safety brought by technology through intelligent acquisition equipment hardware with artificial intelligence algorithm analysis and camera hardware with artificial intelligence image analysis. Customers can pay flexibly according to their needs. This model greatly enhances the high possibility of artificial intelligence companies landing. Use big data analysis and cloud computing technology to provide customers with a series of solutions such as warehouse management, sales forecasting, big data analysis, and financial management. In the SaaS market, there are no domestic enterprises with scale and brand effect in terms of market segmentation, so they mainly cooperate with manufacturers in CRM, HCM, OA, and other aspects.

\section{Digital Entrepreneurship Model}

2.1. Artificial Intelligence. Artificial intelligence is a new science and technology with great potential for development. It has gradually entered the field of social production and services from experimental research, with an increasingly wide range of applications, and has entered the field of cultural industries. At the same time, the specific concepts of artificial intelligence are constantly being adjusted and improved, involving multidisciplinary theories. To study the relationship between artificial intelligence and the cultural industry, the concept and development process of artificial intelligence must first be sorted out. Therefore, it can be understood that artificial intelligence does not refer to a technology, but with the deepening and expansion of research, the general term refers to a number of technologies with "intelligent" performance that has been continuously developed, which is generally considered to be the current fourth technological revolution. At present, the technologies such as image recognition, video recognition, semantic understanding, speech synthesis, machine translation, and sentiment analysis that are already well known by the public belong to the category of artificial intelligence. They are the simulation, extension, and expansion of human intelligence, Medical and other industries play an important role [5].

Artificial intelligence improves the efficiency of cultural production and operation, just like industrial machines replace human manual labor. Artificial intelligence can imitate humans to complete repetitive actions and simple tasks through computer vision technology, natural speech processing technology, and natural language processing technology. It will replace human brain work and assist or replace humans in certain fields. Artificial intelligence can also truly understand consumers based on consumption data and to a certain extent alleviate the imbalance between supply and demand of cultural products. More importantly, the emergence of artificial intelligence provides new ideas for the optimization of the entire macrocultural industry supply structure. Through technology, we can deeply understand the consumer side, adhere to the main role of the market in the configuration, stimulate the vitality of the cultural market, and realize the realization of various regions. The supply and demand balance of enterprises and various cultural products will build a virtuous circle of the cultural industry chain [6].

$$
T=\left[R_{1} s_{1}+R_{1} w_{1}, \ldots, R_{m} s_{m}+R_{m} w_{m}\right]^{T}, \quad m \in M,
$$

where $w_{m}$ represents that it will be transmitted to $\mathrm{HU}_{m, 2}$. Cooperative node $\mathrm{HU}_{m, j}$ received signal [7]:

$$
U_{m, j}^{d}=H_{m, j} \mathrm{WPs}+N_{m, j} \text {. }
$$

Through further analysis, it is found that the information transmission representation [8] is

$$
\begin{aligned}
R_{m, j}^{d}= & H_{m, j} W_{m} \sqrt{P_{m}^{d}}\left(A_{m} s_{m}+B_{m} w_{m}\right) \\
& +H_{m, j} \sum_{j \neq m} W_{i} \sqrt{P_{i}^{d}}\left(A_{i} s_{i}+B_{i} w_{i}\right) .
\end{aligned}
$$


The ZFBF matrix $Q$ will be generated according to the CSI conditions of all cooperating nodes [9].

$$
Q=(T)^{T}=(T)^{T}\left(T T^{T}\right)^{-1},
$$

where [10]

$$
T_{m, 1}^{d}=\frac{p_{m}^{d}\left|h_{m, 1} w_{m}\right|^{2} \alpha_{m}^{2}}{\chi^{2}} .
$$

After a series of processing by the cooperative node, the corresponding $T_{m, 1}^{d}$ can be expressed as [11]

$$
T_{m, 1}^{d}=\frac{p_{m}^{d}\left|h_{m, 1} w_{m}\right|^{2} \alpha_{m}^{2}}{\chi^{2}} .
$$

2.2. Cloud Computing. Cloud computing is a dynamic, easily scalable, and usually virtualized computing method realized through the Internet. MEC enhances the ability of mobile devices to run resource-intensive applications. When the current network connection speed cannot fully meet the user's data transmission needs, or when the computing resources of mobile devices are in short supply, it can accelerate the data flow, service, and application operating speed in the network. As an authoritative standards organization in the industry, $3 \mathrm{GPP}$ is formulating corresponding specifications and introducing new network architectures and technologies to promote the development of MEC. The computing task scheduling in the mobile edge environment can be classified as a wireless interaction model. This model captures the user throughput in the cellular network interaction. The physical layer channel access strategy (CDMA) allows all mobile users to efficiently share the same spectrum resources at the same time. In the next chapter, this article will also extend the model to the multiuser network environment of the macrobase station and the basic base station and consider the caching mechanism [12]. [13]

The SINR corresponding to $\mathrm{HU}_{m, 2}$ can be expressed as

$$
T_{m, 2}^{d}=\frac{P_{m}^{d}\left|h_{m, 2} w_{m}\right|^{2} \beta_{m}^{2}}{P_{m}^{d}\left|h_{m, 2} w_{m}\right|^{2} \alpha_{m}^{2},+\sigma^{2}}+\sigma^{2} .
$$

After that, through Shannon's formula, the maximum downlink transmission rate that each cooperating node $\mathrm{HU}_{m, j}$ can achieve is [14]

$$
R_{m, j}^{d}=W \log _{2}\left(1+T_{m, j}^{d}\right)+T_{m, j}^{d} .
$$

The uplink transmission signal $S$ transmitted to the control node CU is [15]

$$
S=H_{m, 1}^{H} \sqrt{P_{m, 1}^{u} S_{m, 1}}-N_{m, 1} .
$$

Among them, $p_{m, 1}^{u}$ represents the transmit power of $S$ uplink transmission. $a_{n}>0$ represents the user to offload the computing task to the MEC side to run through the wireless channel [16]:

$$
a_{n}=0 \cup M \text {. }
$$

Then get $a_{n}=\left(a_{1}, a_{2}, \ldots, a_{n}\right)$ task scheduling strategy for all users. When the mobile user chooses to schedule tasks to the cloud, the data uplink transmission rate is [17]

$$
V=K \log _{2}\left(1+\frac{s_{n}}{N}\right)
$$

where $K$ is the channel broadband. This article also ignores the time and energy consumption in the process of returning data from the MEC cloud to the user, because most scenarios and applications in mobile edge computing, such as the Internet of vehicles, facial recognition, and virtual reality, often have large input data, but MEC calculates the return based on the input data. The user's result set data level is much lower than the input data, so ignoring this part of the cost is not included in the total cost calculation process [18].

2.3. Digital Entrepreneurship. On the basis of ensuring that the project team continues to provide financial value to the enterprise, the technology development department gradually weakens the project team members, strengthens the human resources of the core product team, and reduces the enterprise's operating costs for the project. As an internal and external communication channel, the marketing department, on the one hand, constructs a product marketing plan based on the product, actively communicates the landing effect of the entrepreneurial cloud platform, and feeds the effect back to the core development team $[19,20]$. The team improved the product in accordance with the standardized process on the basis of feedback, and the process was iteratively virtuous. On the one hand, the finance department controls the company's operating costs, and on the other hand, it formulates financial plans to provide strong financial support for new products in the development stage when they have not received positive compensation. The entire operation process plan will continue to output product value under the guarantee of financial health and obtain the corresponding value return and product positive cycle [21]. The company's internal operations under the new model are shown in Figure 1.

In the case of local computing, all computing tasks are run on the local mobile terminal, and the total cost is $[22,23]$

$$
K_{n}^{l}=\lambda t+\lambda e .
$$

In the case of cloud computing, the total cost can be expressed as [24]

$$
K_{n}=\lambda\left(t\left(a_{n-1}\right)+t_{n}\right)+\lambda\left(e\left(a_{n-1}\right)+e\right) .
$$

The profit distribution formula is $[25,26]$

$$
\phi_{i}^{(r)}=\sum_{i} w(|e|)\left[v(s)-v\left(\frac{s}{y}\right)\right] .
$$

Among them, $\phi_{i}^{(r)}$ is the largest cooperation benefit [27]. 


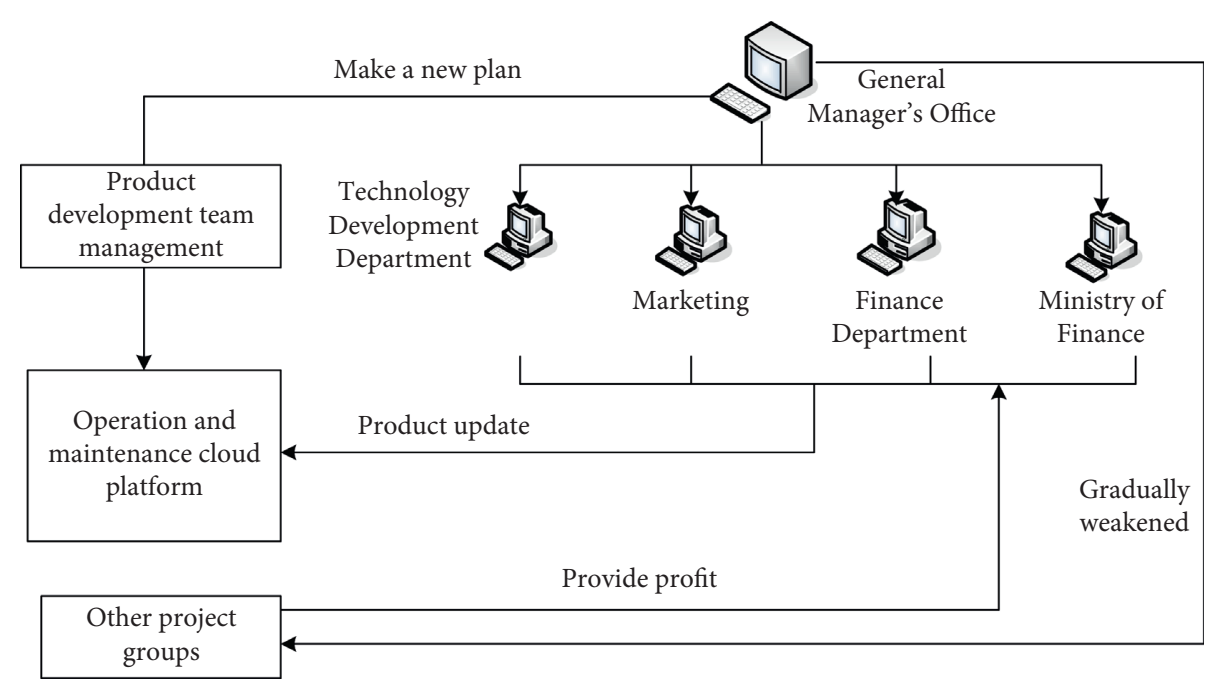

FIGURE 1: The company's internal operations under the new model.

\section{New Framework Experiment of Digital Entrepreneurship Model}

3.1. Evaluation Index System of Entrepreneurial Environment. Based on the principles of relevance, suitability, and systemicity, eight first-level indicators of the entrepreneurial environment evaluation index system are selected, which are the natural environment system, the social environment system, the economic environment system, the intellectual support system, the industrial support system, the social service system, legal policy support system, and financing support system.

3.1.1. Natural Environment System. The superior natural environment is conducive to attracting entrepreneurs. It is reflected by three indicators: geographic location, industrial resources, and residential environment. Industrial resources can provide rich material resources for all kinds of enterprises to ensure the smooth progress of production; a good living environment can attract all kinds of talents to settle down and provide comfortable environmental conditions for the conduct of scientific research activities [28].

3.1.2. Social Environmental System. The social environment mainly affects residents' consciousness and way of thinking and examines the impact of social value orientation, lifestyle, and institutional ethics on entrepreneurial activities. It is reflected by three indicators, namely, the social security system, the social cultural environment, and the social credit situation. It reflects whether the region has a relatively complete social security system, whether it has values that encourage risk-taking and allow failure, and whether the social credit system is sound.

3.1.3. Economic and Environmental System. Its main indicators include per capita GDP, GDP annual growth rate, and total industrial output value, reflecting the regional economic growth and economic efficiency level.
3.1.4. Intellectual Support System. The core element of innovative enterprises is scientific research results, and the source and vitality of technology depend on the quantity and quality of high-quality talents. The abundance and quality of human resources in a certain area directly affect the birth rate and development speed of innovative enterprises. The intellectual support system can be reflected in two aspects: the abundance of human resources and the employment system in the region.

3.1.5. Industrial Support System. The growth of innovative companies is closely related to the industries where they are located. The industrial support system has a special strategic value for the regional entrepreneurial environment, and can reflect the advantages and disadvantages of the regional entrepreneurial environment to a large extent. On this basis, from the concentration of high-tech industries, the degree of relevance of various industries, and the high-tech industry, the contribution of technology industry to the economy and the government's support to high-tech industries are used to evaluate the industrial support in the region [29].

3.1.6. Social Service System. Innovative enterprise entrepreneurship not only is vulnerable to factor supply, such as capital, talent, technology, and information, but also suffers from the impact of market and technology. Therefore, the growth of innovative enterprises needs to obtain information such as business management, legal affairs, and Internet. Services, technical support, and other aspects of services put forward certain requirements for the regional social service system, so the social service system has become a very important part of the entrepreneurial environment.

3.1.7. Legal Policy Support System. Innovative enterprises, as a kind of initial establishment, are inherently faced with various resource bottlenecks. If the outside world is still facing some unknown and chaotic market competition systems, or vacillating policy measures, it will inevitably lead 
to entrepreneurs' insecurity. Adaptation leads to the bankruptcy of entrepreneurship. Therefore, whether the government can formulate a sound legal system, stable policy measures, and build an open, fair, and stable market competition environment is very important for the emergence and development of new enterprises.

3.1.8. Financing Support System. It is generally believed that, in each key stage of the growth of innovative companies, whether the funds needed by the company can be successfully raised becomes the core point of whether the company can continue to develop and grow. Therefore, the financing support system has become a very important part of the entrepreneurial environment evaluation system. However, the growth risks of high-tech companies range from large to small, and the characteristics of income from small to large determine that its financing difficulty is different from that of ordinary enterprises. At the same time, the unique entrepreneurial entities and risks of innovative enterprises also determine the need for government financial support and corresponding funds. Therefore, the indicator is defined in terms of the distribution of financial institutions, the preference of financial institutions to high-tech enterprises, and the degree of risk investment development.

\subsection{Operation Mechanism Innovation. The internal process} mechanism of entrepreneurial enterprise new technology commercialization mainly includes the process model from the vertical perspective and the value creation from the horizontal perspective. In the internal operation process of entrepreneurial enterprise new technology commercialization, the analysis is carried out around the main economic capital elements (technology, capital, market, manpower, and policy) of the characteristic element layer. The internal management process of the commercialization of new technologies in entrepreneurial enterprises is carried out in the four-stage commercialization activities based on the above five economic capital elements, which can be completed through the promotion of entrepreneurial entrepreneurs. The value creation of new technology commercialization of entrepreneurial enterprises is to construct a value chain in line with the commercial activities of new ventures and analyze circular activities around the above five economic capital elements. On this basis, it sums up the different models of entrepreneurial enterprise new technology commercialization from the perspective of internal management, including two major types: the key model of scale production and the key model of business model innovation. The external coordination mechanism of entrepreneurial enterprise new technology commercialization mainly includes vertical perspective network embedding and horizontal perspective network governance. In the process of constructing and coordinating the construction of external networks, the commercialization of new technologies of entrepreneurial enterprises focuses on the analysis of the main social capital elements (trust, cooperation, learning, and communication) at the characteristic element layer. The network embedding of the commercialization of new technologies of entrepreneurial enterprises is aimed at the construction process of entrepreneurial networks, and network governance involves coordinating the interaction and cooperation of all parties in the network. On this basis, we summarized the different models of entrepreneurial enterprise new technology commercialization from the perspective of external collaboration.

3.3. Profit Model Innovation. Artificial intelligence technology has changed the characteristics of products provided by existing competitors that only have one-way value; that is, data is only collected and displayed and still depends on human resources to see and judge through empirical models and manually perform troubleshooting or daily operation and maintenance. The application of artificial intelligence technology in the product makes the value of the product a two-way development; that is, the machine can self-identify faults and errors and resolve and report them. The customer's perspective is unfavorable for artificial intelligence technology, an intangible soft skill. It is speculated that sales should be combined with hardware for main matching, allowing customers to use intelligent acquisition equipment hardware with artificial intelligence algorithm analysis and camera hardware with artificial intelligence. Image analysis feels the convenience, accuracy, and safety brought by technology.

The purpose of technological innovation is to realize value. The application of artificial intelligence technology in enterprise new products enables customers to enjoy the convenience brought by high-tech, while reducing labor costs and energy costs, making direct customers and indirect customers in the industry chain income.

3.4. SaaS Model Innovation. SaaS is the abbreviation of software as the service. It is a model derived from traditional software to reduce customer costs. Previously, it mainly solved some small- and medium-sized B-end customers with high cash flow requirements and transformation needs. The main feature of SaaS is to pay as you use it, without requiring customers to pay high product development costs in one go. The segmented payment happens to solve the problem of high cost of artificial intelligence on a certain level. With the vigorous development of artificial intelligence enterprises, the new acronym AIaS has also emerged, which means artificial intelligence as a service. Customers can pay flexibly according to their needs. This model greatly enhances the high possibility of artificial intelligence companies landing. Use big data analysis and cloud computing technology to provide customers with a series of solutions such as warehouse management, sales forecasting, big data analysis, and financial management.

In the SaaS market, in terms of market segmentation, there are no domestic enterprises with scale and brand effect. Therefore, they mainly adopt collaborative cooperation with manufacturers in CRM, HCM, OA, etc.; the incentive and welfare module will focus on the outsourcing of employee benefits. Relevant value-added services and derivative services are the core business, which can give play to the 
competitive advantages of specialization, scale, and platform, and occupy a leading position in the employee welfare market.

\section{Results and Discussion}

The comprehensive evaluation score of city M's entrepreneurial environment is 89.62 , indicating that the overall entrepreneurial environment of city $\mathrm{M}$ is quite good. Among them, the natural environment system, economic environment system, and legal policy support system are rated as AAA, and the status is "very good," and the social environmental system, intellectual support system, industrial support system, social service support system, and financing support system are rated AA. It is in "good" status, and there is no evaluation index of grades " $\mathrm{A}$ ", "BBB," and "BB." The evaluation of entrepreneurial environment is shown in Figure 2 .

The principle of equity structure design is based on the company's value, in order to make all partners clear about long-term responsibilities, rights, and interests and quantify the contributions of partners. The company's share capital structure is shown in Table 1.

The company's startup time is shown in Figure 3. The research sample is divided according to the number of years of entrepreneurship. Companies with an entrepreneurial life of more than 10 years account for half of the total. This part of the company is in the tracking stage of commercialization: companies with an entrepreneurial life of more than 5 years and less than 10 years account for $45.8 \%$ of the total, and they are commercialized. Only $4.2 \%$ of the companies with an entrepreneurial age of less than or equal to 5 years are in the analysis and development stage of commercialization. Since the publicly listed companies themselves meet a certain degree of standardization and maturity, the Growth Enterprise Market provides a platform for high-tech SMEs to go public. The research sample is divided according to the industry. Among them, the electronic information manufacturing industry accounts for the largest proportion, reaching $39.8 \%$, followed by the chemical industry and the mechanical manufacturing industry, and the pharmaceutical industry and the software industry have a smaller proportion, both less than $10 \%$. It can be seen that the current country's GEM companies that commercialize new technologies are mainly distributed in manufacturing industries such as electronic information manufacturing and machinery manufacturing. Although the software industry and the pharmaceutical industry have developed rapidly, the overall proportion is small. All sample enterprises have obtained high-tech qualification assessment, of which $47.5 \%$ are at the national level and $52.5 \%$ are at the provincial and municipal levels.

In line with the goal of quick start of new projects and long-term development, in the formation of founding team members, talents with common values and complementary abilities and personalities are invited to join the founding team. On this basis, based on the core values of the team, talents are selected comprehensively and carefully from the aspects of ability, character, habits, education, work background, and so on. The positions of the company's team members are shown in Table 2.

It mainly includes PC-side applications, mobile-side applications, and platform applications. Now entering the era of human capital, developer labor costs are relatively high. This part of the investment will account for a large proportion of platform operations, and the first year's cost is expected to be around 2.5 million. Operating expenses, including daily office supplies, marketing and promotion expenses, business entertainment and gift expenses, communication expenses, travel expenses, training expenses, conference expenses, personnel salaries, and other working capital, are expected to be 2 million. The estimated platform capital investment is shown in Table 3.

Platform revenue comes from two major parts: one is the income from platform payment projects of users of government, enterprise, and institution organizations and the other is the sales share and diversion income of individual users' incentives, welfare projects and product exchanges, and self-purchased products and services in the organization. The management part is mainly based on the annual or monthly service fee charged by the organization customers according to the number of members, the customized income of the large-scale organization, and the sales share of the CRM, OA, and other enterprise service modules of the organization application service platform. The platform aims to serve 300,000 enterprise users within five years. 30 million individual users, the number of users in five years, is shown in Table 4.

According to the development forecast of organization customers and individual organization member customers, the income budget is shown in Table 5 .

According to the classification of VAT tax items and tax rates of our country's tax authorities after the business tax reform in 2014, the general taxpayer tax rate for $R \& D$, technical services, and information technology services is $6 \%$. Therefore, this project develops and distributes SaaS software products and sales and service income tax rate is $6 \%$ to pay value-added tax; at the same time, the city maintenance and construction tax and education surcharge are paid in accordance with relevant regulations. The value-added tax and surcharge (ten thousand yuan) are shown in Table 6.

In terms of marketing, a five-year sales plan has been formulated as shown in Figure 4. In 2020, we will mainly cooperate with benchmark customers to create cloud entrepreneurship landing and demonstration effects and collect customer opinions in a timely manner. In the first year of the launch of the new product, the financial goal is to achieve break-even, the market is mainly based on promotion and trial, and the negotiation of intentional partners is the main focus.

According to the previous budget of inputs and costs, the following will budget the income statement and cash flow statement of this project for 2018-2021 and conduct financial analysis on the basis of the budget to provide a reference for investment decision-making. The monthly profit is shown in Figure 5.

The company's annual expenses are shown in Figure 6. The cash paid to employees from 2018 to 2020 shows a 


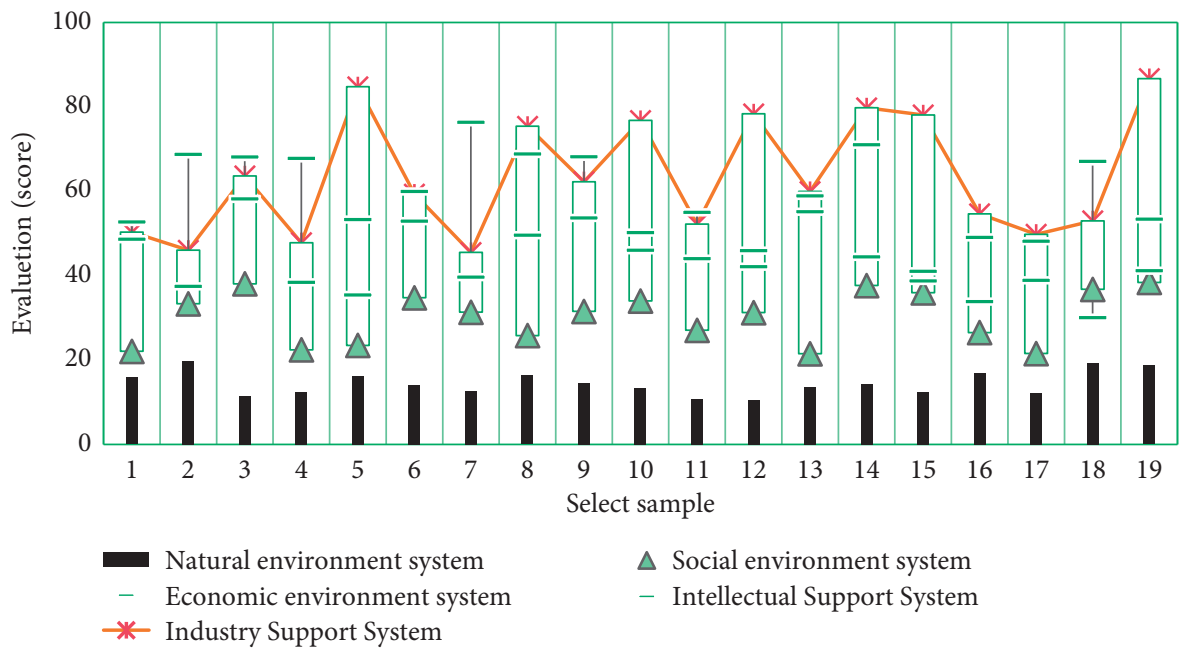

FIGURE 2: Evaluation of entrepreneurial environment.

TABle 1: Company's share capital structure.

\begin{tabular}{lccccc}
\hline Company shareholder & $\begin{array}{c}\text { Equity ratio before } \\
\text { financing (\%) }\end{array}$ & $\begin{array}{c}\text { Angel postshare } \\
\text { ratio }(\%)\end{array}$ & $\begin{array}{c}\text { Share ratio after } \\
\text { round A (\%) }\end{array}$ & $\begin{array}{c}\text { Share ratio after } \\
\text { round B (\%) }\end{array}$ & $\begin{array}{c}\text { Share ratio after round C } \\
(\%)\end{array}$ \\
\hline Core founder (CEO) & 65 & 58.50 & 46.80 & 39.78 & 35.80 \\
Core founding team & 15 & 13.50 & 10.80 & 9.18 & 8.26 \\
(CTO, COO) & 20 & 18.00 & 14.40 & 12.24 & 11.02 \\
Reserve incentive shares & - & $10 \%$ & 8.00 & 6.80 & 15.30 \\
Angel investment & - & - & 20.00 & 17.00 & 13.50 \\
A round of investment & - & &
\end{tabular}

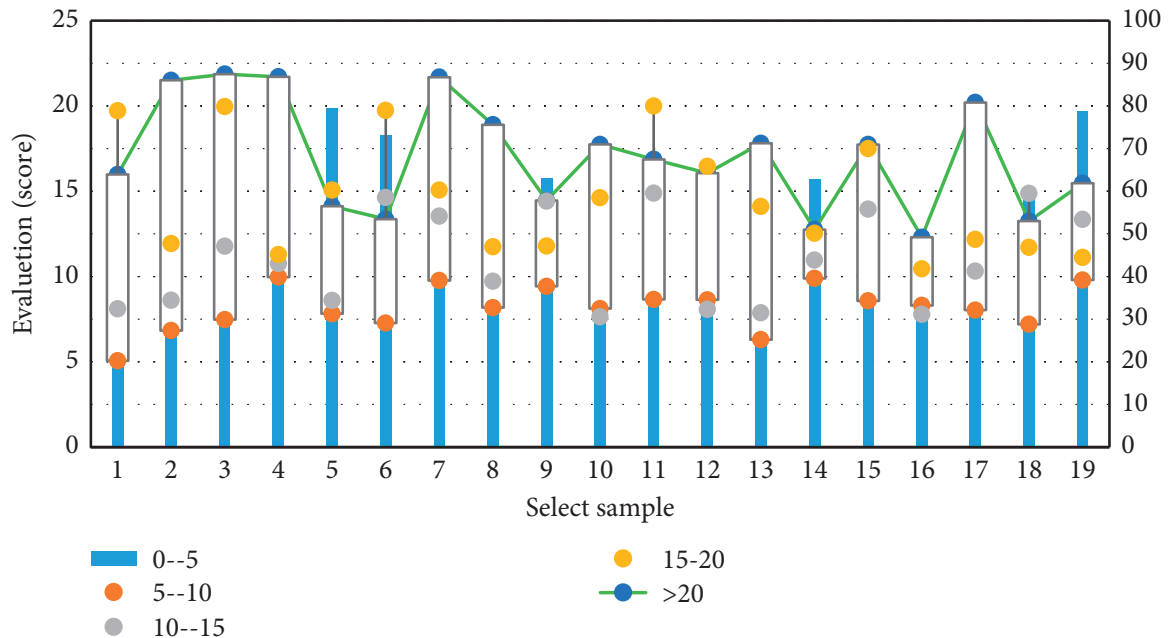

FIgUre 3: Company startup time.

Table 2: Positions of company team members.

\begin{tabular}{lcc}
\hline Name & Job title & Main duty \\
\hline A & CEO & Responsible for the overall management of the company \\
B & COO & Responsible for product operations \\
C & CMO & Negative marketing and sales management \\
D & CTO & Responsible for technology development \\
\hline
\end{tabular}


TABle 3: Platform capital investment estimate.

\begin{tabular}{|c|c|c|c|c|}
\hline Project & 1 & 2 & 3 & 4 \\
\hline Infrastructure investment & 80 & 100 & 150 & 250 \\
\hline Platform product development & 250 & 350 & 500 & 750 \\
\hline Working liquidity & 170 & 300 & 500 & 1500 \\
\hline Total (ten thousand yuan) & 500 & 750 & 1150 & 2500 \\
\hline
\end{tabular}

TABLE 4: Specific number of users in five years.

\begin{tabular}{|c|c|c|c|c|c|}
\hline Project & 1 & 2 & 3 & 4 & 5 \\
\hline Objective management and incentive system & 0.5 & 2 & 5 & 10 & 30 \\
\hline Custom system & 0.01 & 0.02 & 0.1 & 0.5 & 1 \\
\hline Platform distribution & 0.2 & 1 & 3 & 5 & 15 \\
\hline Incentive and benefit distribution & 5 & 20 & 50 & 100 & 300 \\
\hline
\end{tabular}

TABLE 5: Revenue budget.

\begin{tabular}{lcccc}
\hline Project & 1 & 2 & 3 & 4 \\
\hline Target management and incentive and welfare system income & 500 & 2000 & 5000 & 10000 \\
Custom system revenue & 1000 & 2000 & 10000 & 50000 \\
Platform distribution revenue & 120 & 600 & 1800 & 300000000 \\
Incentive and benefit distribution & 5000 & 20000 & 50000 & 100000 \\
\hline
\end{tabular}

TABLE 6: Value-added tax and surcharge (ten thousand yuan).

\begin{tabular}{|c|c|c|c|c|c|}
\hline Species & 1 & 2 & 3 & 4 & 5 \\
\hline VAT & 374.72 & 1392.45 & 3781.13 & 9226.42 & 24849.06 \\
\hline Urban maintenance and construction tax & 26.23 & 97.47 & 264.68 & 645.85 & 1739.43 \\
\hline Education surcharge & 11.24 & 41.77 & 113.43 & 276.79 & 745.47 \\
\hline Total & 412.19 & 1531.70 & 4159.25 & 10149.06 & 27333.96 \\
\hline
\end{tabular}

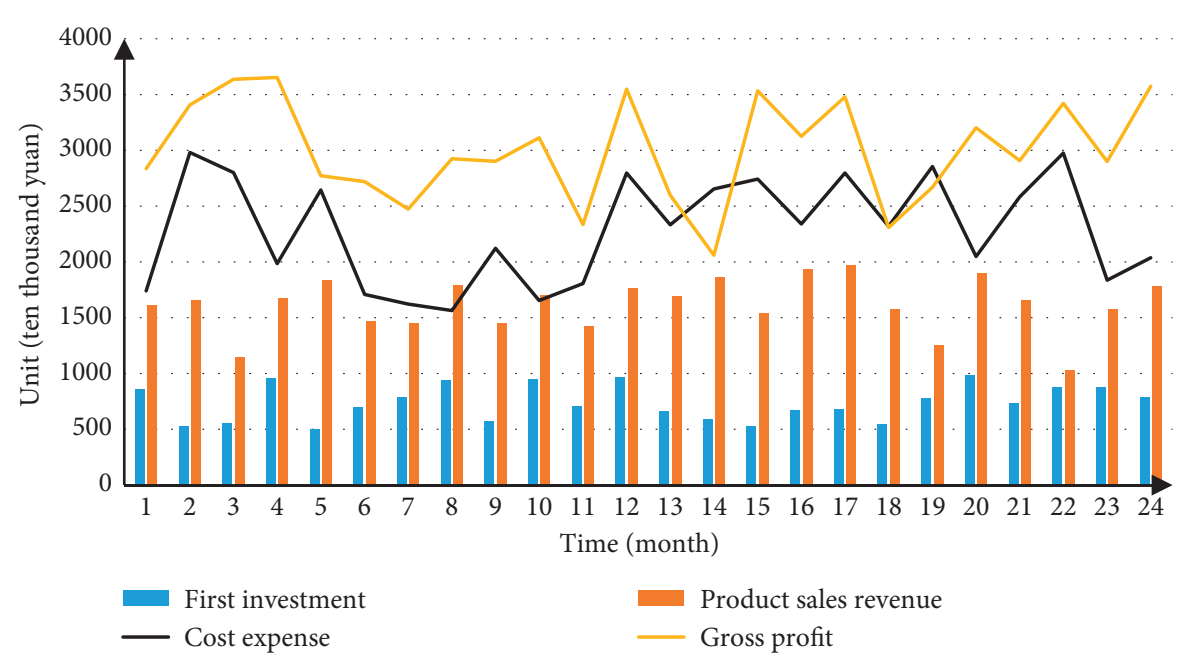

Figure 4: Annual sales plan.

gradual increase, and the taxes and fees paid are also increasing year by year. The cash paid for other operating activities reached up to 1.230 million yuan in 2018, and the subtotal of cash outflows from operating activities reached up to 200 million yuan.

The medium- and long-term interest rates of the bank of our country are now only $4.9 \%$. Under the current capital environment, based on $i=10 \%$ of the capital cost, the net present value of the project after five years will reach $\mathrm{NPV}=213,621$ million $>0$, the project's rate of return in far capital cost is higher than $10 \%$, and the profitability is strong, indicating that the project is more feasible. The project details are shown in Table 7.

The introduction of top technical talents at home and abroad has reached the scale of large-scale Internet companies, and high R\&D investment has strengthened its 


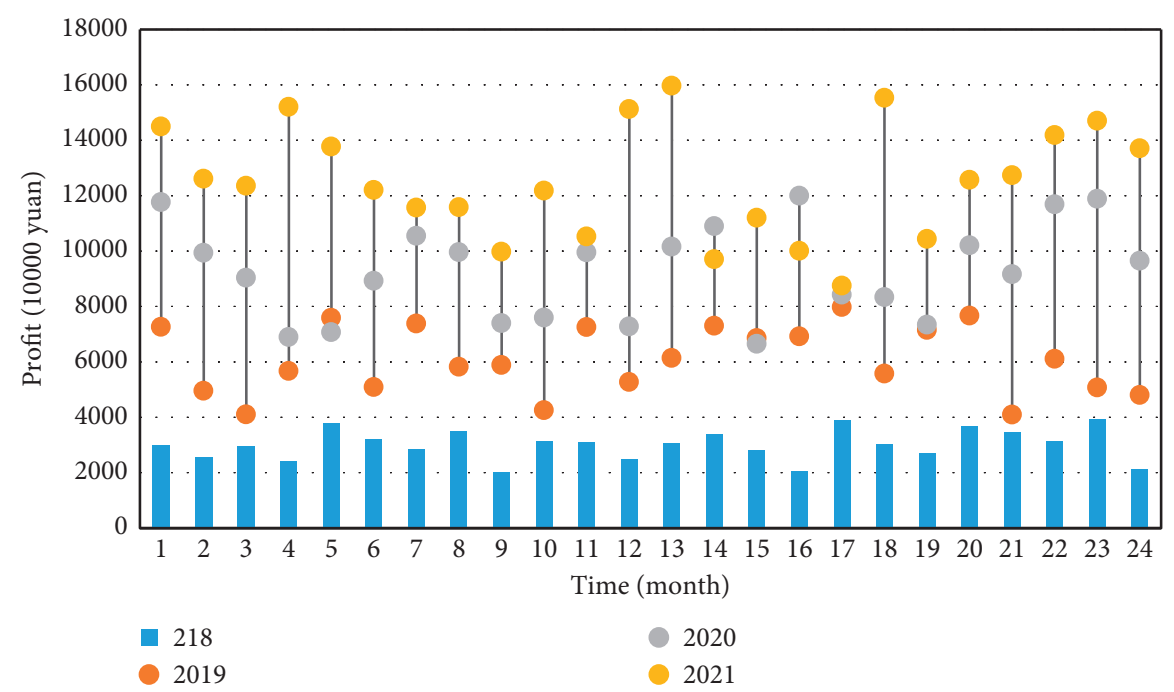

Figure 5: Monthly profit.

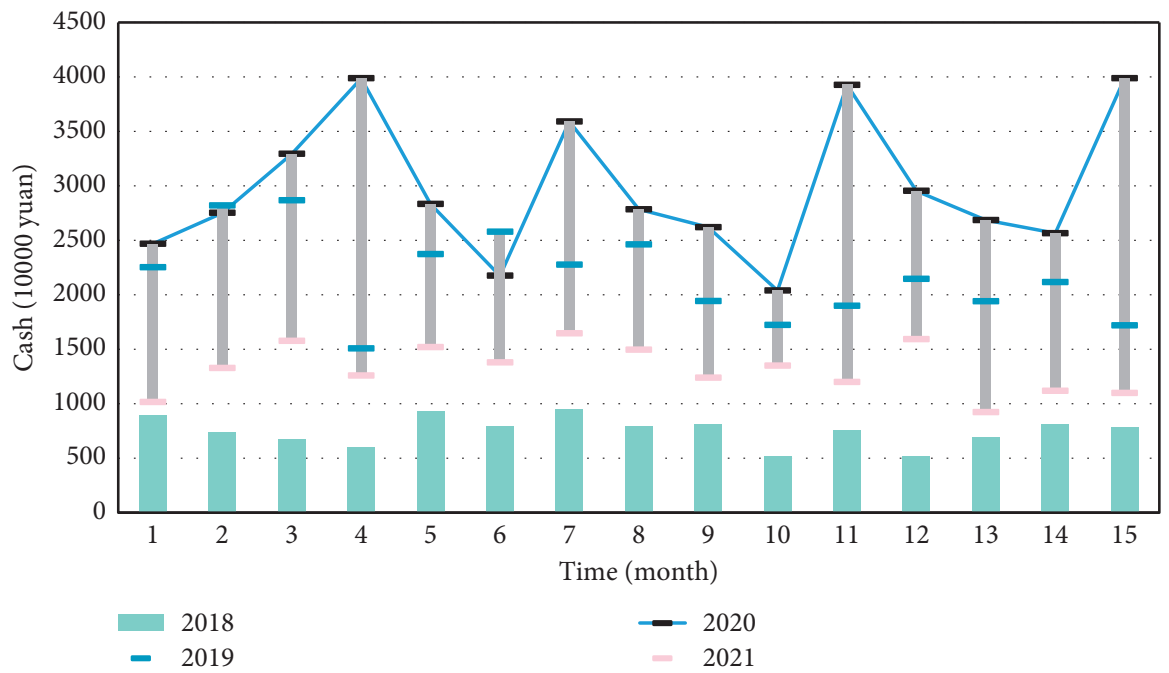

FIgURE 6: The company's annual expenses.

Table 7: Project details.

\begin{tabular}{lcc}
\hline Years & Net cash flow (ten thousand yuan) & $10 \%$ discount rate (ten thousand yuan) \\
\hline 1 & 1806 & 1641 \\
2 & 7514 & 6830 \\
3 & 32250 & 29318 \\
5 & 141400 & 128545 \\
NPV & Net cash flow & 213621 \\
\hline
\end{tabular}

strong scientific and technological strength. As a result, the company's scientific and technological team has obtained more than 1,000 national patents. With the help of scientific and technological power, it has been widely used in the company's organizational model and operation management model. At present, we have mastered important technological technologies such as logistics drones, logistics intelligent equipment, artificial intelligence, and technology. Technology has become the company's primary core competitiveness, which will help the construction of smart logistics platforms. Using technology to make profits is shown in Figure 7. 


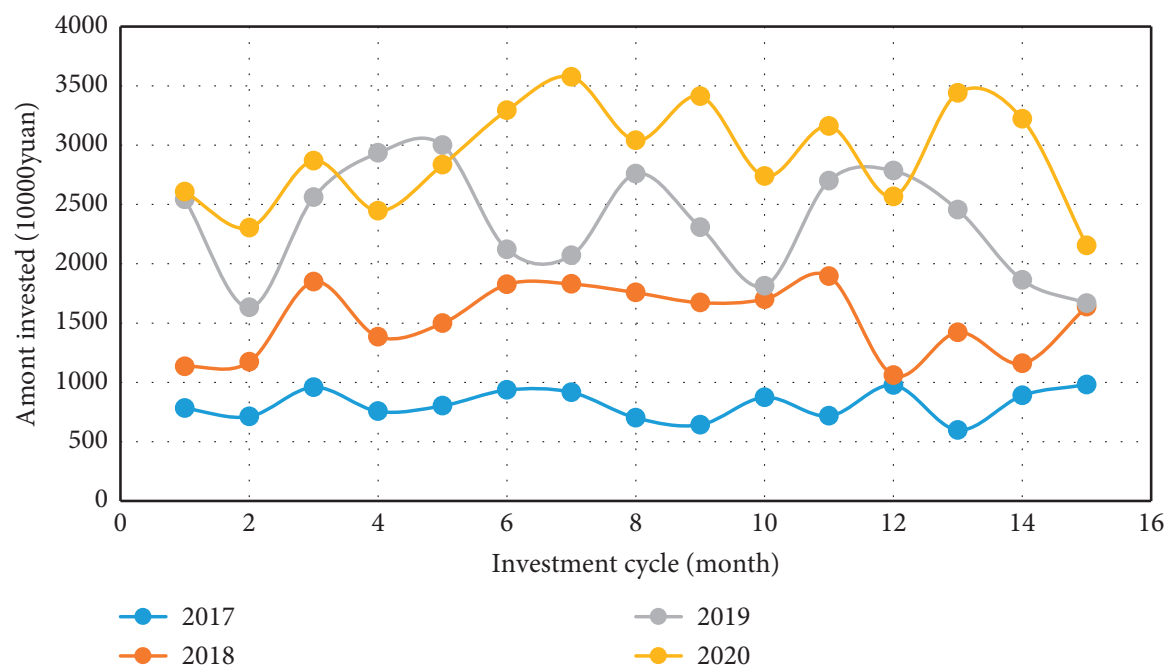

FIGURE 7: Using technology to make profits.

\section{Conclusion}

This study uses artificial intelligence technology to change the products provided by existing competitors that only have the characteristics of one-way value; that is, data is only collected and displayed. Let customers experience the convenience, accuracy, and safety brought by technology through intelligent acquisition equipment hardware with artificial intelligence algorithm analysis and artificial intelligence image analysis. This model greatly enhances the high possibility of artificial intelligence companies landing. Use big data analysis and cloud computing technology to provide customers with a series of solutions such as warehouse management, sales forecasting, big data analysis, and financial management. In the SaaS market, in terms of market segmentation, there are no domestic enterprises with scale and brand effect. Therefore, they mainly adopt collaborative cooperation with manufacturers in CRM, HCM, OA, etc.; the incentive and welfare module will focus on the outsourcing and outsourcing of employee benefits. Relevant value-added services and derivative services are the core business, which can give play to the competitive advantages of specialization, scale, and platform and occupy a leading position in the employee welfare market. This research will promote the innovation of new types of enterprises. However, there are few studies on the risk assessment of new technology commercialization that can reflect the characteristics of entrepreneurial enterprises, which is an important aspect of future research work that needs to be done in depth.

\section{Data Availability}

No data were used to support this study.

\section{Conflicts of Interest}

The authors declare that they have no conflicts of interest.

\section{References}

[1] S. Srinivasamurthy and D. Liu, "Survey on cloud computing security," Journal of Software, vol. 27, no. 6, pp. 1328-1348, 2016.

[2] X. Chen, L. Jiao, W. Li, and X. Fu, "Efficient multi-user computation offloading for mobile-edge cloud computing," IEEE/ACM Transactions on Networking, vol. 24, no. 5, pp. 2795-2808, 2016.

[3] Y. Han, J. Chan, T. Alpcan, and C. Lecki, "Using virtual machine allocation policies to defend against Co-resident attacks in cloud computing," IEEE Transactions on Dependable \& Secure Computing, vol. 14, no. 1, pp. 95-108, 2017.

[4] C. Xu, J. Lei, W. Li, and X. Fu, "Efficient multi-user computation offloading for mobile-edge cloud computing," IEEE/ ACM Transactions on Networking, vol. 24, no. 5, pp. 27952808, 2016.

[5] R. Deng, R. Lu, C. Lai, T. H. Luan, and H. Liang, "Optimal workload allocation in fog-cloud computing toward balanced delay and power consumption," IEEE Internet of Things Journal, vol. 3, no. 6, pp. 1171-1181, 2017.

[6] M. Masdari, S. Valikardan, Z. Shahi, and S. I. Azar, "Towards workflow scheduling in cloud computing: a comprehensive analysis," Journal of Network and Computer Applications, vol. 66, pp. 64-82, 2016.

[7] Z. Cao, J. Lin, C. Wan, Y. Song, Yi. Zhang, and Xi. Wang, "Optimal cloud computing resource allocation for demand side management," IEEE Transactions on Smart Grid, vol. 8, no. 4, pp. 1943-1955, 2017.

[8] H. Cai, B. Xu, L. Jiang, and A. V. Vasilakos, "IoT-based big data storage systems in cloud computing: perspectives and challenges," IEEE Internet of Things Journal, vol. 4, no. 1, pp. 75-87, 2017.

[9] A. A. Soofi, M. I. Khan, "A review on data security in cloud computing," International Journal of Computer Application, vol. 96, no. 2, pp. 95-96, 2017.

[10] H. Abbas, O. Maennel, and S. Assar, "Security and privacy issues in cloud computing," Annals of Telecommunications, vol. 72, no. 5-6, pp. 233-235, 2017.

[11] J. Shen, T. Zhou, X. Chen, J. Li, and W. Susilo, “Anonymous and traceable group data sharing in cloud computing," IEEE 
Transactions on Information Forensics and Security, vol. 13, no. 4, pp. 912-925, 2018.

[12] H. M. Sabi, F.-M. E. Uzoka, K. Langmia, and F. N. Njeh, "Conceptualizing a model for adoption of cloud computing in education," International Journal of Information Management, vol. 36, no. 2, pp. 183-191, 2016.

[13] S. Wang, K. Liang, J. K. Liu, J. Chen, J. Yu, and W. Xie, "Attribute-based data sharing scheme revisited in cloud computing," IEEE Transactions on Information Forensics \& Security, vol. 11, no. 8, pp. 1661-1673, 2017.

[14] M. Guzek, P. Bouvry, and E. G. Talbi, "A survey of evolutionary computation for resource management of processing in cloud computing," IEEE Computational Intelligence Magazine, vol. 10, no. 2, pp. 53-67, 2016.

[15] M. Anshari, Y. Alas, and L. S. Guan, "Developing online learning resources: big data, social networks, and cloud computing to support pervasive knowledge," Education and Information Technologies, vol. 21, no. 6, pp. 1663-1677, 2016.

[16] S. Wang, J. Zhou, J. K. Liu, J. Yu, J. Chen, and W. Xie, "An efficient file hierarchy attribute-based encryption scheme in cloud computing," IEEE Transactions on Information Forensics and Security, vol. 11, no. 6, pp. 1265-1277, 2017.

[17] J. H. Thrall, X. Li, Q. Li et al., "Artificial intelligence and machine learning in radiology: opportunities, challenges, pitfalls, and criteria for success," Journal of the American College of Radiology, vol. 15, no. 3, pp. 504-508, 2018.

[18] S. Singh and I. Chana, "A survey on resource scheduling in cloud computing: issues and challenges," Journal of Grid Computing, vol. 14, no. 2, pp. 217-264, 2016.

[19] A. F. Barsoum and M. A. Hasan, "Provable multicopy dynamic data possession in cloud computing systems," IEEE Transactions on Information Forensics \& Security, vol. 10, no. 3, pp. 485-497, 2017.

[20] J. L. Tsai and N. W. Lo, "A privacy-aware authentication scheme for distributed mobile cloud computing services," IEEE Systems Journal, vol. 9, no. 3, pp. 805-815, 2017.

[21] M. Abdullahi, M. A. Ngadi, and S. i. M. Abdulhamid, "Symbiotic organism search optimization based task scheduling in cloud computing environment," Future Generation Computer Systems, vol. 56, pp. 640-650, 2016.

[22] G. Somani, M. S. Gaur, D. Sanghi, and M. Conti, "DDoS attacks in cloud computing: collateral damage to non-targets," Computer Networks, vol. 109, pp. 157-171, 2016.

[23] E. Cavalcante, J. Pereira, M. P. Alves et al., "On the interplay of Internet of things and cloud Computing: a systematic mapping study," Computer Communications, vol. 89-90, pp. 17-33, 2016.

[24] V. Yevgeniy and K. Murat, "Adversarial machine learning," Synthesis Lectures on Artificial Intelligence and Machine Learning, vol. 12, no. 3, pp. 1-169, 2018.

[25] R. Liu, B. Yang, E. Zio, and X. Chen, "Artificial intelligence for fault diagnosis of rotating machinery: a review," Mechanical Systems and Signal Processing, vol. 108, pp. 33-47, 2018.

[26] M. Hutson, "Artificial intelligence faces reproducibility crisis,” Science, vol. 359, no. 6377, pp. 725-726, 2018.

[27] T. Hirasawa, K. Aoyama, T. Tanimoto et al., "Application of artificial intelligence using a convolutional neural network for detecting gastric cancer in endoscopic images," Gastric Cancer Official Journal of the International Gastric Cancer Association \& the Japanese Gastric Cancer Association, vol. 87, no. Suppl 1, pp. 1-8, 2018.

[28] T. Grubljesic, P. S. Coelho, and J. Jaklic, "The shift to socioorganizational drivers of business intelligence and analytics acceptance," Journal of Organizational and End User Computing, vol. 31, no. 2, pp. 37-64, 2019.
[29] L. Fabisiak, "Web service usability analysis based on user preferences," Journal of Organizational and End User Computing, vol. 30, no. 4, pp. 1-13, 2018. 